\title{
Análisis de las fuentes de información Internacional en la prensa española. Las primeras guerras del siglo XXI
}

\author{
Rosana FuENTES FERNÁNDEZ \\ Universidad San Jorge (Zaragoza) \\ rfuentes@usj.es
}

Recibido: 23 de enero de 2012

Aceptado: 29 de octubre de 2012

\begin{abstract}
Resumen
El presente trabajo expone el análisis de las fuentes de información que tres medios nacionales, $A b c, E l$ Mundo y El País, y uno regional, el Heraldo de Aragón, hicieron en las primeras guerras del siglo XXI. El objeto de este estudio se aborda a través de un análisis cuantitativo de 337 crónicas en prensa de las coberturas de Alfonso Rojo, Juan Cierco, Gervasio Sánchez y Ángeles Espinosa; y del enfoque cualitativo, de 11 entrevistas en profundidad a los autores de las crónicas y otros periodistas. Las conclusiones y sus interpretaciones se centran en las fuentes de información más utilizadas y el grado de decisión de los reporteros.
\end{abstract}

Palabras clave: Fuentes de información, prensa española, Internacional, conflictos.

\section{Analysis of the International information sources in Spanish press. The early XXI century wars}

\begin{abstract}
This work describes the analysis of the sources of three national media, Abc, El Mundo and El País, and one regional, the Heraldo de Aragón, about the early twenty-firt century wars. The result of the quantitative study of 337 chronic press coverage of Alfonso Rojo, Juan Cierco, Gervasio Sánchez and Ángeles Espinosa. The qualitative approach based in 11 in-depth interviews with the authors of the chronicles and other journalists. The conclusions and their interpretations is the space for discussion: know the sources of information used and the degree of decision of the reporters.
\end{abstract}

Keywords: Information sources, Spanish media, International, conflicts.

Referencia normalizada: FUENTES FERNÁNDEZ, Rosana (2012): “Análisis de las fuentes de información Internacional en la prensa española. Las primeras guerras del siglo XXI“. Estudios sobre el mensaje periodístico, vol. 18, núm. 2 (julio-diciembre), págs.: 475-490. Madrid, Servicio de Publicaciones de la Universidad Complutense.

Sumario: 1. Introducción. 2. Objetivos y metodología. 3. Resultados; 3.1. Fuentes oficiales; 3.2. Testigos; 3.3; Fuentes documentales; 3.4. Ayuda; 3.5. Observadores. 4. Conclusiones. 5. Referencias bibliográficas. 6. Entrevistas de la autora.

\section{Introducción}

Durante una cobertura informativa bélica, los enviados especiales disponen de sus propias fuentes de información o, en su defecto, las reciben de sus antiguos compañeros en el cargo o por mediación de los medios de comunicación. Las informaciones del corresponsal pueden proceder de miembros del Gobierno, fuerzas militares, los diplomáticos o testigos de los acontecimientos. Entre esas fuentes, destacarían los informadores desplazados a esos conflictos o corresponsales extranjeros.

La naturaleza de ciertas ofensivas y el interés que despiertan hacen posible que algunos medios se planteen la necesidad de crear corresponsalías en una región, país o 
incluso continente. El riesgo en estos casos, se encuentra ante la imposibilidad de cubrir un espacio tan amplio mediante un solo reportero motivo por el que los medios recurren también a la cobertura de agencias. En España, la información que la prensa traslada sobre conflictos sigue una marcada tendencia en materia de cobertura internacional: los hechos relevantes se cubren a través de los enviados especiales, corresponsales ofreelances $\mathrm{y}$, los breves, mediante agencias, mientras que la prensa regional se nutre de informaciones de agencias debido al escaso presupuesto para esa sección y en el menor de los casos, a través de freelances.

Cuando los medios solo se sirven de agencias, cuentan únicamente con el apoyo de fuentes indirectas, insuficientes si se quiere conocer de primera mano las consecuencias del conflicto (MORENO, 1999). Los diarios nacionales, por lo general, disponen de corresponsalías en diversas zonas. Tal es el caso de El País (431.033 ejemplares) y El Mundo (323.587 unidades), periódicos de mayor difusión en España (AEDE, 2010: 46-47), que se sirven de corresponsales en el extranjero para cubrir la información y obtener datos más cercanos de los hechos.

La labor del reportero no se limita a seleccionar las vías de información, ha de decidir el número de consultas que les va a trasladar. Un tema muy debatido ya que $a$ priori el número de fuentes no es lo primordial siempre que el reportero localice buenas vías para hacer una información lo más fiel posible a realidad. Por ejemplo, un flujo informativo plural e intenso es positivo, pues sirve al lector para contrastar la información. En este sentido, Héctor BORRAT (1989: 93) señala que mediante esta vía el periódico no tendría la necesidad de usar la información filtrada o investigada o a la inversa.

Para conocer la cobertura informativa internacional en la prensa española se desarrolla el análisis de contenido acotando la investigación a cinco guerras. La primera contienda seleccionada fue la del Golfo en 1991, por sus implicaciones en los posteriores conflictos y la repercusión que tuvo para España debido al trabajo del enviado especial de $E l$ Mundo, Alfonso Rojo, único periodista español que informó desde Bagdad. La invasión de Irak de 2003, también cubierta por Rojo en el mismo diario, se eligió debido al elevado despliegue informativo por parte de los medios de comunicación. El análisis comparativo en la cobertura informativa de Rojo en ambos conflictos permitió conocer los cambios que se gestaron en un mismo campo de batalla con apenas una década de diferencia. El siguiente conflicto analizado fue la guerra de Afganistán en 2001, centrado en la caída del régimen Talibán a través de la enviada especial de El País Ángeles Espinosa desplazada en Pakistán, que se acercó al lugar de los hechos finalizada la guerra. Cierran el estudio, la cobertura del corresponsal de $A b c$ Juan Cierco en la Segunda Intifada entre Israel y los Territorios Palestinos Ocupados y la de Gervasio Sánchez para el Heraldo de Aragón en calidad de freelance en la Guerra Civil en Sierra Leona.

Tras la definición del estado de la cuestión, donde la elección de las fuentes de información es fundamental para la consecución de la pieza periodística, el presente estudio continúa con los objetivos y la metodología. En dicho apartado, se explican las técnicas de investigación utilizadas. A continuación, se indaga en las fuentes de información empleadas por los cuatro reporteros analizados. El ensayo prosigue con el 
resultado informativo de los casos examinados que dependió, en gran medida, de la censura a la que se vieron sometidos los periodistas y su ubicación. El apartado final, lo constituyen las conclusiones respecto al tratamiento informativo.

\section{Objetivos y metodología}

El principal objetivo de este trabajo es dar respuesta a las siguientes preguntas: ¿Cuáles son las fuentes de información más utilizadas durante las primeras guerras del siglo XXI? ¿La elección del reportero es libre o está condicionada? El objeto de estudio han sido las fuentes de información de la prensa diaria y más concretamente de $E l$ País, Abc, El Mundo y Heraldo de Aragón. Para la selección de los medios se tuvo en cuenta su carácter de líderes del sector respecto a su tirada y difusión con el fin de obtener la máxima y mejor representatividad. Puesto que se trata de medios de referencia, en los tres primeros casos en el ámbito nacional y el último, en el regional, las conclusiones mostrarán el predominio de unas fuentes de información sobre el resto. Los resultados obtenidos forman parte de una investigación de mayor alcance relacionada con las estrategias informativas durante las primeras guerras del siglo XXI. El caso de cuatro corresponsales españoles de prensa.

Las dificultades a la hora de contactar con las distintas fuentes de información, la ubicación de los reporteros o la censura a la que estuvieron expuestos, fueron algunos de los motivos por los que se combinaron métodos cualitativos y cuantitativos. Para los primeros se desarrollaron 11 entrevistas en profundidad centradas en la persona con el propósito de conocer sus experiencias vividas. Para disponer de la máxima variedad de puntos de vista, en la selección de los entrevistados se intentó que estuvieran representados los autores de las crónicas así como otros especialistas en la materia.

Se eligió el método de entrevistas semiestructurado con un cuestionario que garantizaba la obtención de una información y un grado de libertad que permite mantener una conversación más abierta, donde lo importante es la experiencia del individuo. En la puesta en marcha y desarrollo de las 11 entrevistas se tuvieron en cuenta los aspectos recogidos por María Jesús MERINO (2010: 48) respecto al conocimiento previo que ha de tener el entrevistador/a, que en este caso es periodista e investiga sobre el ámbito informativo internacional, lo que facilita la obtención de la máxima información. La selección de los entrevistados relacionados con las crónicas seleccionadas. El lugar y el momento para realizar la entrevista, que fue elegido por el entrevistado para así facilitar la realización de la misma. La elaboración de una guía con las preguntas o temas básicos a tratar, que se iban trasladando a lo largo del diálogo o la duración de la entrevista, que rondó alrededor de las dos horas.

Las informaciones secundarias partieron de 337 crónicas en prensa de las coberturas de Alfonso Rojo, Juan Cierco, Gervasio Sánchez y Ángeles Espinosa. En la guerra del Golfo se hizo un seguimiento de 29 crónicas de Rojo publicadas en El Mundo entre el 17 de enero y el 7 de marzo de 1991. En la Segunda Intifada se efectuó un rastreo de la cobertura de la corresponsalía en Jerusalén de Cierco desde el inicio del conflicto, el 29 de septiembre, hasta el 2 de diciembre de 2000 mediante el análisis de 107 crónicas. Durante la invasión de Irak, cubierto de nuevo por Alfonso Rojo, se desglosaron las 21 crónicas escritas en El Mundo entre el 19 de marzo y 9 de abril de 
2003. En la caída de los Talibán, se analizaron 159 crónicas de Espinosa en el transcurso de 130 días, desde el 16 de septiembre al 10 de diciembre de 2001. Por último, en la Guerra Civil en Sierra Leona, se seleccionó el Heraldo de Aragón porque efectuó una cobertura amplia del conflicto: entre el 20 al 30 de enero de 1999, el 14 al 26 de mayo del 2000 y el cuatro al 9 de enero de 2001, donde se exponen los resultados del estudio de las 21 crónicas que escribió Gervasio Sánchez desde Freetown, capital sierraleonesa.

\section{Fuentes de Información}

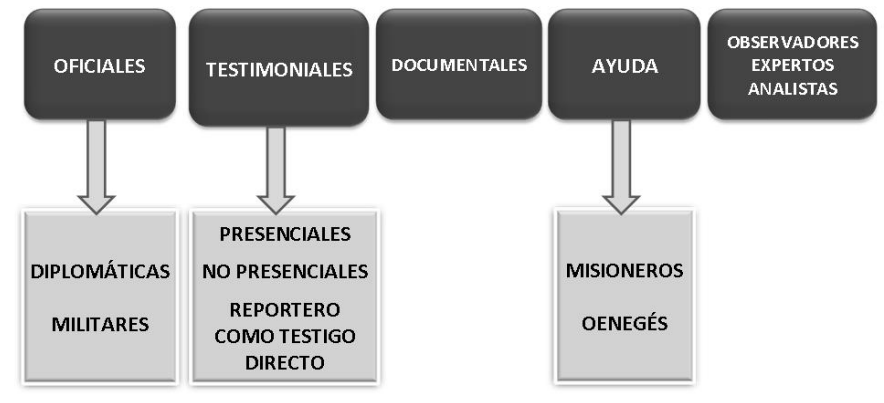

\section{ESQUEMA}

La unidad de análisis se corresponde con cada fuente de información que aparece en las 337 crónicas revisadas, en total, se examinan 784 . El corpus de la investigación tiene en cuenta los resultados obtenidos y divide las fuentes en cinco bloques: Oficiales, Testimoniales, Documentales, Ayuda y Observadores, cuyos resultados se mostrarán por separado en este estudio.

El estudio adecua el análisis a los hábitos de los cuatro enviados especiales de cuyos resultados se desprende el uso de las fuentes Oficiales, Documentales, Testigos, Observadores y Ayuda. En cada apartado se incluirá un cuadro-resumen, donde de forma visual se apreciarán las diferencias que se dieron respecto al uso de las fuentes de información en los distintos conflictos.

\section{Resultados}

\subsection{Fuentes Oficiales}

Todos los estados del mundo disponen de unos resortes a través de los cuales se canaliza la información de su fuente oficial. El uso de este tipo de datos es fundamental para el conocimiento del conflicto. De hecho, la función del periodista debe "consistir en vigilar el poder", como apunta Amira HASs (2005: 15).

La mayoría de los medios de información tienden a recurrir con bastante regularidad a las fuentes oficiales llámense gobierno, empresas u otros organismos. Sin embargo, lo verdaderamente relevante radica en el papel que desempeñan actualmente dichas fuentes, que se han convertido en un porcentaje muy alto de las que emplean los medios de comunicación de casi todo el mundo, convertidos en meros portavoces.

En los países no democráticos, como el caso de Irak, esta forma de proceder hace más visible la propaganda y manipulación de la información. Sin embargo, en los países europeos, como Francia o el Reino Unido, disponen de distintos portavoces gubernamentales y servicios de prensa en los diversos ministerios, a través de los cuales se comunican con los medios. "En España tales misiones corresponden al ministerio 
del Portavoz del Gobierno y a los distintos servicios de prensa de los ministerios, incluida la oficina de Información Diplomática del ministerio de Asuntos Exteriores y, desde luego, la DRISDE (Dirección de Relaciones Informativas y Sociales de Defensa)" (PizArRoso, 2005: 102).

Las embajadas son otra vía de acceso para conocer la opinión de expertos diplomáticos, también las fuerzas del ejército, ambas englobadas dentro de las fuentes oficiales en este estudio. Los esfuerzos en el campo diplomático llevados a cabo durante las guerras son constantes. En el caso de las fuentes militares, la censura en sus informaciones es habitual en tiempos de guerra. Felipe SAHAGún (1986: 282) explica que el corresponsal sigue siendo un engranaje más de la gran maquinaria bélica, y salvo excepciones, no suele ser soldado.

De las cinco guerras analizadas mediante el enfoque cuantitativo se muestra el predominio de las fuentes oficiales respecto al resto en la Segunda Intifada, la Guerra contra los Talibán y la invasión de Irak. Juan Cierco, Ángeles Espinosa y Alfonso Rojo, recurrieron en primer término a las informaciones oficiales, que en total suman 364 unidades.

Fuente Oficial: Cuadro resumen

\begin{tabular}{|l|l|c|c|c|}
\hline Diario & Conflicto & Posición & Unidades & \% del total \\
\hline El Mundo & Golfo, 1991 & $2^{\mathrm{a}}$ & 38 & 33 \\
\hline ABC & Segunda Intifada, 2000 & $1^{\mathrm{a}}$ & 91 & 60 \\
\hline Heraldo de Aragón & Sierra Leona, 2001 & $2^{\mathrm{a}}$ & 18 & 26 \\
\hline El País & Talibán, 2001 & $1^{\mathrm{a}}$ & 191 & 46 \\
\hline El Mundo & Invasión Irak, 2003 & $1^{\mathrm{a}}$ & 26 & 61 \\
\hline
\end{tabular}

En el transcurso de la Invasión de Irak, Alfonso Rojo recurre con asiduidad a las fuentes militares occidentales, pero carece de información del ejército contrario. En el caso, de Juan Cierco más del 90 por ciento de las veces se sirve de los altos cargos palestinos como el ministro de Sanidad, Riad Zoadnum; los líderes Yaser Arafat y Hasan Nasralah o el ministro de información Yaser Abed Rababo, entre otros, a pesar de que en un chat (diálogo a través de La Red) en la edición digital del diario afirma que "se conoce mejor un conflicto cerca de los seres humanos que lo padecen cada día y no de los políticos que lo dirigen en la distancia”. El motivo, según explica CiERCO (2008), pudo deberse a que "en esa etapa las fuentes políticas fueron muy importantes".

En las informaciones sobre los Talibán se aprecian contradicciones entre enviados especiales y las versiones oficiales'. Ángeles EspinOsA (2006) indicó que las fuentes oficiales tiraron cada una por su lado, "pero luego los periodistas nos buscábamos la vida y contrastábamos. Personalmente, casi a diario, además de esa información para el récord, apoyaba mi crónica con algún reportaje o una entrevista, cuando no con

${ }^{1}$ Un ejemplo de las contradicciones mencionadas se reflejó en la crónica de EsPINOSA del 12 de octubre de 2001 en El País, donde las fuentes oficiales afirmaron que "estas declaraciones de la corresponsal de Al Yazira contradicen la versión oficial de los talibán, que han calificado de 'mentira' las afirmaciones estadounidenses de que 'no se está atacando objetivos civiles"”. 
ambos. Sé que mucha gente leía mis crónicas, no solo en España, pero había muchos otros periodistas y cada uno tiende a leer o ver a los que escriben o hablan en su idioma".

La mayor parte de las fuentes de información oficiales utilizadas por Espinosa proceden de Pakistán y, en menor medida, de Afganistán el país de los talibán. El estudio desveló que gran cantidad de las informaciones oficiales provinieron de fuentes no identificadas por la enviada especial. En todos los casos, las militares partieron del bando oriental, puesto que por su situación solo pudo obtener las informaciones occidentes a través de los medios de comunicación, en especial de los radiofónicos.

La poca fiabilidad de las noticias hace que Ángeles Espinosa se encuentre con un número considerable de fuentes no identificadas que restan credibilidad a sus informaciones. En la crónica del 23 de octubre de 2001, la periodista pone en duda los datos provenientes de los talibán, como hace en otras informaciones, ya que suelen ser bastante difusos ${ }^{2}$.

Los viajes organizados por el Ministerio de Información durante la Guerra del Golfo de 1991 tampoco hicieron fácil el trabajo de los periodistas al limitar sus movimientos. Los reporteros eran recogidos en el hotel al Rashid y conducidos en microbuses hacia lugares estratégicos para el Gobierno. Con el mismo fin, el régimen entregaba comunicados a la prensa que después Alfonso Rojo incluía en muchas de sus crónicas especificando la procedencia. En otras ocasiones, el enviado especial no mencionó donde se habían hecho públicos los comunicados oficiales, simplemente se limitó a transmitir las informaciones.

Rojo también aprovechó sus crónicas para contar las decisiones que tomaron en su entorno y que le pudieron afectar. Un ejemplo se dio en la información del 6 de marzo de 1991 cuando relató cómo los funcionarios del Ministerio de Información avisaron a los periodistas extranjeros que iban a ser expulsados ${ }^{3}$. La constante presencia de los funcionarios iraquíes también fue explotada por el reportero para exponer las prohibiciones y obligaciones que, sobre todo, impusieron los miembros del Ministerio de Información a los periodistas extranjeros. Sadún al Janabi, jefe del protocolo del Ministerio de Información, porfiaba para que vieran cada edificio y fotografiasen cada esquina.

De igual forma, muchas de sus crónicas trasladaron a los lectores el incesante seguimiento de los guías del Gobierno iraquí hacia los periodistas occidentales. Estas tácticas fueron orquestadas por Sahún, encargado de reunir a los reporteros y pedirles en más de una ocasión que cooperasen con ellos para obtener más facilidades. Al-

2 En la crónica del 1 de octubre de 2001 se aprecia cómo los informadores talibán tienden a la imprecisión para dar sus informaciones. Ej.: "ambigüedad que caracteriza todas sus declaraciones". Ángeles ESPINOSA reconoce las consecuencias de la ausencia de información franca cuando en la crónica del 2 de octubre de 2001, aclara que "la falta de información directa hace que aparezcan manifestaciones contradictorias".

3 El Ministerio de Información iraquí advirtió que los visados, que permitían en aquellos momentos a más de un centenar de corresponsales extranjeros permanecer en Irak, no serían renovados. A medida que fueran expirando los periodistas serían "invitados" a salir rumbo a Jordania. 
fonso Rojo (1995: 137) cuenta cómo los funcionarios les daban indicaciones muy precisas a la hora de escribir sus crónicas ${ }^{4}$. En definitiva, la estricta vigilancia de los guías del Ministerio de Información hacia los periodistas occidentales y la permanencia en el hotel al Rashid impidió a Rojo acceder a distintas fuentes de información o desplazarse con libertad entre las filas del ejército.

En Sierra Leona, Gervasio SÁNCHEZ (2007) se acercó en varias ocasiones al gobierno para conocer qué pasaba, informaciones que, "a veces utilicé porque me interesó y otras no". En lo que respecta a sus crónicas, no se queja en ningún momento de las fuentes oficiales, que identificó sin problema. Sin embargo, criticó la tendencia de las citadas fuentes a intentar que los periodistas preparen publirreportajes ${ }^{5}$. En varias ocasiones, le propusieron irse a Afganistán para hacer un reportaje sobre los militares españoles y les contestó que no. Afirma que, en todo caso, él haría un trabajo sobre Afganistán y de paso algo sobre los militares españoles. "Lo que no voy a hacer", matiza, "es un trabajo de promoción de los soldaditos españoles en Afganistán, voy a buscar la historia que me interesa: la del conflicto".

\subsection{Testigos (las fuentes testimoniales)}

La mayoría de los testigos son individuos que padecen directamente las consecuencias de la guerra y, en muchas ocasiones, argumentan porqué ocurren unos u otros acontecimientos. Un alto porcentaje son gente normal, de la calle, ciudadanos de a pie que dan su punto de vista desde su experiencia vital. Francisco Peregil (2008) prefiere a los testigos presenciales y no presenciales, pues su objetivo parte por hablar con esa gente. Si no entiende su idioma busca traductores no oficiales como estudiantes que sepan inglés para poder entrevistar a quien le interese.

La cercanía al conflicto capacita al testigo como una muy buena fuente de información. Mónica LeIVA (2008) identifica la capacidad para "hacer entender la tragedia de su día a día a través de la empatía que puedan despertar y tratar de transmitir una identidad elaborada durante un siglo a base de sufrimiento y supervivencia". A menudo, es la única manera de enterarse de las cosas. Mónica G. PRIETO (2008) tiende a "empezar trabajando con una persona local de confianza que esté bien informada y que sepa cómo moverse, y una vez que tienes una idea lejana de lo que está ocurriendo hay que acercarse al lugar y preguntar en persona".

Ramón LoBo (2007) considera estas vías de información como las más idóneas. Tesis compartida por Alfonso ARMADA (2007): “Cuando estás allí, recurres a lo que tienes delante, la gente con la que te encuentras, tus propios ojos, lo que ves, lo que

${ }^{4}$ Indicaciones de los funcionarios iraquíes a los periodistas extranjeros: "Punto número 1: no se pueden pasar informaciones sobre los daños sufridos por instalaciones estratégicas. Punto número 2: queda prohibido incluir datos logísticos importantes. Punto número 3: antes de enviar, es imprescindible que nos enseñen sus crónicas".

5 Pieza que promueve los mensajes de una organización desde un punto de vista editorial, en el que se prima la noticia por encima de cualquier otro interés, ya sea comercial, corporativo o político. 
escuchas, y si es una voz de refugiados, lo que hay allí,...". El periodista entiende que depende del lugar, "si estás en la capital del país y está estable, te entrevistas con gente del gobierno, de la oposición, con periodistas locales si tienes acceso a ellos, también con gente de la calle".

Al margen de la ubicación, la regla fundamental para un corresponsal de guerra es la de saber mimetizarse, renunciar a los discutibles y narcisistas beneficios del exceso de protagonismo a favor de las bastante más útiles ventajas del anonimato. Esto hizo siempre Ryszard KAPUSCINSKI (2002: 10), que viajó mucho sirviéndose de toda clase de medios de transporte disponibles. Si le hubieran reconocido como extranjero, como diferente, es posible que la gente le hubiera dirigido la palabra, "pero sin duda no se habría lanzado con la misma libertad a hacer comentarios y observaciones sinceras".

En las guerras mencionadas, el acceso a los testigos dependió de la libertad de movimientos de los periodistas más que de su capacidad para mimetizarse. Siguiendo los resultados de los análisis cuantitativos, dos de las guerras analizadas, la del Golfo y la Guerra Civil en Sierra Leona, los testigos suponen la primera fuente informativa. Dentro del ranking de las más utilizadas en las cinco contiendas expuestas, los testigos tanto presenciales como no presenciales e incluso el periodista como fuente directa se sitúan en segunda posición con 179 unidades.

Fuente Testigos: Cuadro resumen

\begin{tabular}{|l|l|c|c|c|}
\hline Diario & Conflicto & Posición & Unidades & \% del total \\
\hline El Mundo & Golfo, 1991 & $1^{\mathrm{a}}$ & 49 & 43 \\
\hline ABC & Segunda Intifada, 2000 & $2^{\mathrm{a}}$ & 34 & 23 \\
\hline Heraldo de Aragón & Sierra Leona, 2001 & $1^{\mathrm{a}}$ & 25 & 37 \\
\hline El País & Talibán, 2001 & $3^{\mathrm{a}}$ & 61 & 15 \\
\hline El Mundo & Invasión Irak, 2003 & $2^{\mathrm{a}}$ & 10 & 23 \\
\hline
\end{tabular}

El predominio de las informaciones provenientes de los testigos presenciales como de los no presenciales por parte de Alfonso Rojo en la Guerra de 1991 se debe a la mayor accesibilidad a las mismas. Durante su periplo en Irak, Rojo presenció los acontecimientos de forma directa o personalmente -testigo directo o fue informado por los testigos indirectos-. En su calidad de espectador, contó de primera mano las informaciones como protagonista de lo que relataba. Sin embargo, en una entrevista, Alfonso Rojo (2005) afirma no haber sido testigo del conflicto, según sus propias palabras, porque apenas vio la guerra. En la mayoría de las ocasiones, los entrevistados fueron los civiles alcanzados por las bombas del Ejército de la coalición.

La importancia que adquieren las crónicas de Rojo por ser el único periodista español desplazado en Bagdad hace que El Mundo incluya a partir del 25 de enero de 1991 en la contraportada una nueva sección titulada "Testigo Directo". Espacio que el enviado especial aprovechó para justificar alguna de las circunstancias que le impidió desarrollar bien su trabajo, ya que sus informaciones partieron del hotel al Rashid debido a la escasa movilidad que le permitieron los funcionarios del Ministerio de Información. Las imposiciones a las que fueron sometidos los corresponsales o los viajes que programaron los funcionarios, perjudicaron el acceso a estas fuentes. 
En el caso de Sierra Leona, las víctimas fueron los testigos más utilizados. Las fuentes de información partieron de los hospitales, a los que Gervasio Sánchez recurrió con asiduidad para conocer el estado de las víctimas de los grupos armados. Además de los heridos, recurre al personal sanitario o a la avalancha humana que intenta conseguir algo de ayuda humanitaria o aquellos que huyeron de su pueblo por miedo a los enfrentamientos.

Frente al conflicto del Golfo y la Guerra Civil en Sierra Leona, los tres enfrentamientos restantes ocupan las segundas y terceras posiciones en las fuentes más utilizadas. En el caso de la invasión de Irak, la posición de Alfonso Rojo con el ejército aliado hace difícil el acceso a otras informaciones. Respecto a la labor de Juan CIERCO (2008) durante la Segunda Intifada, a pesar del escaso número de testigos que aparecen en sus crónicas, considera que un periodista no debe abstraerse del dolor que le rodea: "Ese es uno de mis enfoques como corresponsal en una zona de conflicto, intentar ponerle nombre y apellido a las víctimas, compartir con ellas su dolor, su frustración, su falta de esperanza. Creo que se conoce mejor un conflicto cerca de los seres humanos que lo padecen cada día y no de los políticos que lo dirigen en la distancia".

En la guerra contra los Talibán, Ángeles Espinosa tampoco da demasiada relevancia a estos testigos, puesto que en la mayoría de las crónicas no menciona el oficio al que se dedican u otros datos sobre la persona entrevistada. La dificultad con la que se encontró a la hora de transmitir las informaciones le hizo recurrir a la recomposición de los hechos a partir del relato de testigos presenciales.

\subsection{Fuentes Documentales}

Se puede acceder a las fuentes documentales a través de instancias que organizan estos datos para su posterior consulta a través de los archivos de los diarios, de la televisión, la radio, bibliotecas públicas y personales, o mediante colecciones especializadas, boletines, material filmado, de radio, etc. También pueden seguirse en tiempo real desde los distintos medios de comunicación.

Por lo general, los reporteros se decantan por el uso de la radio como medio informativo u otras vías como Internet, ya que es más rápido y accesible a la hora de dar noticias. "Siempre puedes llevar un pequeño aparato en el bolsillo con un auricular o incluso usar el teléfono móvil como radio, ya estés en un coche o andando por la calle", asegura Mónica G. PRIETO (2008). Otros se decantan por los medios locales, incluso por colegas con experiencia sobre el terreno, como el caso de Mikel AYESTARÁN (2008) que también se sirve de libros de referencia y muchos viajes a la zona para sentir en primera persona, ya que según el periodista, "es imposible hacerse una idea de lo que ocurre en los Territorios sin haberlos visitado".

El acceso de los periodistas a las zonas en conflicto tampoco evitó la censura, que se dio a pesar de la gran cantidad de enviados especiales desplegados en territorio afgano y en los países vecinos. La preferencia por ciertos informadores también está presente como ocurrió en la guerra del Golfo, donde la $C N N$ predominó sobre el resto. Uno de los ejemplos más claros fue la captación de imágenes del conflicto, solo autorizada a la cadena árabe Al Yazira. El resto de las televisiones solo pudieron recuperar las imágenes que daba la cadena árabe u obtenerlas de forma clandestina, como hizo la $C N N$. 
El análisis cuantitativo desvela que las fuentes documentales ocupan la tercera posición dentro de las más utilizadas en las primeras guerras del siglo XXI con un total de 148 unidades. A pesar de ser una cifra elevada ninguno de los conflictos se decantaron por esta fuente de información de forma preferente.

Fuente Documental: Cuadro resumen

\begin{tabular}{|l|l|c|c|c|}
\hline Diario & Conflicto & Posición & Unidades & \% del total \\
\hline El Mundo & Golfo, 1991 & $3^{\text {a }}$ & 27 & 24 \\
\hline ABC & Segunda Intifada, 2000 & $3^{\text {a }}$ & 24 & 16 \\
\hline Heraldo de Aragón & Sierra Leona, 2001 & $4^{\text {a }}$ & 9 & 13 \\
\hline El País & Talibán, 2001 & $2^{\text {a }}$ & 82 & 20 \\
\hline El Mundo & Invasión Irak, 2003 & $3^{\text {a }}$ & 27 & 24 \\
\hline
\end{tabular}

La censura se valió de múltiples vías para evitar problemas con los periodistas, que a menudo eran confinados en los hoteles "por su seguridad". Ángeles Espinosa plasmó en la crónica del 11 de octubre de 2001 las amenazas que sufrirían los informadores si entraban de forma ilegal en Afganistán, los talibán les advirtieron que serían tratados como cualquier soldado estadounidense descubierto en territorio afgano.

Tampoco les permitieron presenciar el desarrollo de los combates, por tanto los chalecos antibalas que llevaron muchos cronistas les sirvieron de poco en la guerra de la propaganda de la que fueron testigos. La falta de movilidad afectó a la información manejada a conveniencia de unos y otros. Espinosa confiesa en la crónica del 7 de noviembre de 2001 que un día no supo si los talibán habían derribado un helicóptero estadounidense y habían matado a sus cuatro ocupantes, tal y como le habían informado. La propia Embajada talibán admitió en varias ocasiones, que carecía de datos por la dificultad de las comunicaciones.

Las fotografías también estuvieron prohibidas. Ahmed RASHID (2001: 116) cuenta cómo unos periodistas que recorrieron el pabellón femenino de un hospital de la ciudad, costeado por la Unión Europea, fueron detenidos por tomar fotografías de las pacientes, ya que los talibán habían prohibido los testimonios gráficos. Sin embargo, los altos cargos sí hicieron un uso indiscriminado y premeditado de los medios de comunicación. Susan SonTAG (2002: 61) critica "la unanimidad de la retórica moralizante emitida sin límites por los dirigentes y por los medios de comunicación estadounidenses en los últimos días para enmascarar la realidad no es digna de una democracia madura".

Además del yugo de las fuerzas políticas, el hecho de que algunos periodistas pagasen para hacer viajes organizados a Afganistán pudo ser uno de los motivos por los que Ángeles Espinosa recogió en sus informaciones las exclusivas que sacaron otros medios de comunicación como hizo el 11 de noviembre de 2001.

En la invasión de Irak de 2003, prosigue la censura hacia los informadores, ya que tanto las tropas de ocupación en Irak como los insurgentes coincidieron en su preferencia por tener a los periodistas lejos. Sus secuelas, recuerda Carolina PODESTÁ (2005), "son el llamado 'periodismo por control remoto' o 'periodismo de hotel', los enojos de amplias capas de la población iraquí con Al Yazira y de los periodistas, árabes y no árabes, con las tropas de la ocupación". 
Ya en la Guerra del Golfo de 1991, el propio Gobierno iraquí interesado en la repercusión de los medios facilitaba información a los periodistas a través de improvisadas "salas de prensa de campaña" en el bar Scherezade. Pese a dicha circunstancia, Alfonso Rojo accede también a noticias de los medios de comunicación iraquíes. Cuando empezó el bombardeo, se vio obligado a ver el telediario desde el refugio del hotel, en la zona reservada a los empleados del Rashid. El enviado especial veía los partes de guerra sentado en el suelo, entre los botones sudaneses, los camareros indios, los limpiadores bengalíes y los empleados iraquíes ${ }^{6}$.

En el transcurso de la Segunda Intifada, Juan Cierco consulta todo tipo de medios de carácter local o internacional para ampliar su información. Sin embargo, constatamos que se trata de pocos ejemplares y que muchos de ellos no fueron identificados, realidad que contrasta con la variedad de medios que existe tanto en los Territorios Palestinos Ocupados como en Israel.

Por último, en el caso de Gervasio SÁnchez (2007) en la Guerra Civil en Sierra Leona escribe la historia que visualmente puede controlar, la zona de trabajo la tiene muy reconocida. Además tiende a acotar. Si se decanta por efectuar un reportaje del miedo, trabajará más que alguien que se dedica a artículos de muertos, porque después de conseguir a 10 personas distintas en Bagdad, escribirá un reportaje bueno. En cualquier caso, en el transcurso del análisis de sus crónicas se confirma cómo también recurre en varias ocasiones a las cifras para ampliar las informaciones.

\subsection{Ayuda}

Los conflictos destruyen las economías del país, que necesitan un fuerte impulso para volver a funcionar, motivo por el que numerosas oenegés se desplazan a estas zonas, lo que supone una fuente de información para los periodistas. Otra alternativa de Ayuda son los misioneros que, instalados antes del conflicto en cierta zona normalmente deprimida, están muy bien informados al disponer de radios internas o saber lo que está pasando más allá de donde el enviado especial puede llegar.

Tanto misioneros como oenegés son fuentes de información asequibles para los reporteros, quienes llegan incluso a alojarse con ellos. Ana CAMACHO (2008) permaneció durante bastante tiempo en la misión "San Juan de Díos" en Liberia. Cuando les cortaron el teléfono, copiaba las crónicas, las imprimía y se acercaba al aeropuerto. Allí buscaba a alguien para que en Villan o Freetown las llevara a un télex.

$\mathrm{Al}$ albor de los resultados cuantitativos la fuente denominada Ayuda, donde se engloba a los misioneros y las oenegés, queda relegada a la cuarta posición con un total de 53 unidades desarrolladas. Fuente a la que acudieron Gervasio Sánchez en la Guerra sierraleonesa y Ángeles Espinosa en la caída de los Talibán. En ambos conflictos, ocuparon la tercera y la cuarta posición consecutivamente.

${ }^{6}$ A las ocho en punto de la noche, el telediario comenzaba con unas imágenes del presidente Sadam Husein en un sillón blanco. A su alrededor están los altos jerarcas del régimen: los miembros del Consejo Supremo de la Revolución que gobierna Irak. No se oyen voces, ni comentarios. Sólo música clásica de fondo. Después aparece un locutor que comienza a leer las noticias, alternándose con otro. No hay imágenes de guerra, ni filmaciones. Solo comunicados. Rojo, El Mundo, 28 de enero de 1991. 
Fuente Ayuda: Cuadro resumen

\begin{tabular}{|l|l|c|c|c|}
\hline Diario & Conflicto & Posición & Unidades & \% del total \\
\hline El Mundo & Golfo, 1991 & - & - & - \\
\hline ABC & Segunda Intifada, 2000 & - & - & - \\
\hline Heraldo de Aragón & Sierra Leona, 2001 & $3^{\text {a }}$ & 14 & 20 \\
\hline El País & Talibán, 2001 & $4^{\text {a }}$ & 39 & 10 \\
\hline El Mundo & Invasión Irak, 2003 & - & - & - \\
\hline
\end{tabular}

Ángeles Espinosa plasmó la importante función de estas organizaciones no gubernamentales, puesto que identificó a los trabajadores que entrevistó con nombre, apellidos y trabajo concreto. Estos miembros que, en su mayoría, provenían de países occidentales, trabajaron para oenegés con distintos perfiles. El hecho de que los periodistas recurran a estas organizaciones no gubernamentales, según Tim AlLEN y Jean SEATON (1999: 96), hace que les resulta difícil desarrollar una perspectiva radicalmente distinta a la agencia. A pesar de estos problemas, las organizaciones no gubernamentales fueron para ESPINOSA (2006) una fuente muy útil para conocer detalles de la sociedad afgana. Algunas recibieron noticias de su personal local y las compartieron con ellos.

En Sierra Leona, Gervasio Sánchez recurrió en numerosas ocasiones a los misioneros. La difícil situación del país le llevó a no identificar a cuatro de los nueve predicadores que entrevistó para preservar su seguridad. SÁNCHEZ (2007) considera que se trata de fuentes muy bien informadas: "Tienen radios internas, saben lo que está pasando donde tú no puedes llegar. Las oenegés también disponen de equipos para informarse. Te pueden dar la información más completa para hacer una historia. Casi siempre vas muy forzado con el tiempo". Afirmación que comparte Alfonso ARMADA (2007), quien considera que estas organizaciones pueden dar buena información, "aunque hay algunas que son más objetivas que otras".

\subsection{Observadores}

En lo que respecta a la temática informativa, en las cinco guerras analizadas los medios de comunicación normalmente se limitaron a informar sobre crisis, motines u otros sucesos dramáticos sin el uso de voces especialistas en la materia. En el ámbito académico, Noam CHOMSKY (2003: 17) afirma que "los expertos, salvo raras excepciones, se preocupan en gran medida de las manipulaciones de los grupos gobernantes y de qué posibilidades tienen para garantizar la estabilidad".

Para contrarrestar estas carencias informativas, los enviados especiales suelen llevar documentación de referencia con el propósito de complementar sus crónicas. En este apartado, se vislumbra dicho recurso en tres de las cinco contiendas analizadas. Tanto Juan Cierco como Gervasio Sánchez y Ángeles Espinosa invitan al lector a profundizar en los postulados de algunos especialistas o simplemente mencionan algunas de sus argumentaciones. Pese al esfuerzo de los tres reporteros, la fuente denominada Observadores ocupa la última posición en el cómputo global con tan solo 40 unidades de análisis entre las crónicas de la Segunda Intifada, la Guerra Civil en Sierra Leona y la caída de los Talibán. 
Fuente Observadores: Cuadro resumen

\begin{tabular}{|l|l|c|c|c|}
\hline Diario & Conflicto & Posición & Unidades & \% del total \\
\hline El Mundo & Golfo, 1991 & - & - & - \\
\hline ABC & Segunda Intifada, 2000 & $4^{\text {a }}$ & 2 & 1 \\
\hline Heraldo de Aragón & Sierra Leona, 2001 & $5^{\text {a }}$ & 3 & 4 \\
\hline El País & Talibán, 2001 & $5^{\text {a }}$ & 35 & 9 \\
\hline El Mundo & Invasión Irak, 2003 & - & - & - \\
\hline
\end{tabular}

En términos generales, Gervasio SÁnchez (2007) critica la escasez de expertos de guerra: "Normalmente están en sus casas escribiendo tonterías". Durante los años que el periodista gráfico lleva informando en zonas de conflicto, ha visto muy pocos especialistas trabajando en el campo de batalla, sí coincidió con algunos periodistas u otros profesionales que conocen bien el país hace muchos años y la situación porque vivieron otras parecidas. El reportero matiza que en España se tratan los temas de forma simplista. En sus viajes al extranjero, lleva ejemplares de referencia. Cita a Kapucinsky, "cuyas obras son más leídas desde su muerte". Sánchez se nutre también de los observadores, sin embargo, no les da tanta importancia como Ángeles Espinosa, quien consultó con frecuencia a fuentes expertas en la materia.

En las crónicas sobre la caída de los Talibán, Espinosa muestra abiertamente sus preferencias informativas. De los siete observadores que consultó, da mayor importancia a Ahmed Rashid que, según ella, "es la máxima autoridad en el tema. También está el profesor Rubin, de la Universidad de Nueva York, pero tiene menos experiencia sobre el terreno", según indica el 22 de septiembre de 2001 en El País. Del mismo modo, ofreció a sus lectores la posibilidad de ampliar los datos sobre el conflicto afgano por medio de la inclusión de información de algunas de las obras de estos expertos, como "Los talibán" de Rashid o "Reaping the Whirlwind" de Michael Griffin, que analizan la influencia del grupo extremista en Afganistán.

Al margen de Rashid o Griffin, los observadores fueron fuentes no identificadas por petición de los propios entrevistados o porque la enviada especial no lo consideró necesario como en la crónica del 26 de septiembre de 2001. Una práctica desaconsejada en el punto 1.18 del "Libro de estilo de El País" (1990: 17), donde se indica que "hay que evitar el recurso de disimular como fuentes informativas ('según observadores...', 'a juicio de analistas políticos...') aquellas fuentes que solo aportan opiniones. En este supuesto, deberá identificarse a la persona consultada. En otro caso, no resulta interesante conocer una opinión si no se sabe quién la avala".

Para la cobertura de la Segunda Intifada, Juan Cierco solo se sirve de las informaciones de dos expertos: Ron Ben Ishai, especialista en asuntos militares del diario hebreo Yedist Ajronot y Mary Robinson de la ONU, cuyas informaciones apenas tuvieron trascendencia en los medios. Ha de plantearse por tanto qué ocurre con los expertos en el Islam, y por qué sus contribuciones apenas tuvieron cabida en los medios. En esta línea, Edward SAID (1981: 16) considera que: "Nunca ha habido un experto americano en el mundo del Islam cuya audiencia fuera muy amplia; sin embargo, con la excepción del último Marshall Hodgson's tercer volumen sobre La Ventura del Islam, publicado póstumamente en 1975, las informaciones sobre el Islam no eran frecuentes". 
Esta ausencia podría deberse a que la mayoría de los escritores especializados en el mundo islámico no dominaban los lenguajes relevantes, por ese motivo tuvieron que depender de la prensa o de otros escritores del oeste para sus informaciones. SAID (1981: 21) habla de la tendencia "a estudiar y reestudiar, para centrarse en los mismos puntos: las élites, los programas de modernización, el papel de los militares, los grandes líderes visibles o la estrategia geopolítica (desde el punto de vista americano)".

\section{Conclusiones}

El análisis cuantitativo da como resultado que las fuentes oficiales suponen el $46 \%$ de las 784 unidades de estudio, por tanto son las más utilizadas por los reporteros de la prensa española. En segundo lugar, se encuentran los Testigos con un $22 \%$ en el cómputo total, también ubicados en los primeros puestos en su uso y, en tercer lugar, las fuentes Documentales que cuentan con un $18 \%$ del total. Por último, las fuentes de Ayuda y los Observadores ocupan las últimas posiciones con un $6 \%$ y $5 \%$ consecutivamente.

Respecto al uso de las fuentes de información analizadas: Oficiales, Testimoniales, Documentales, Ayuda y Observadores, solo en dos conflictos, la Guerra Civil en Sierra Leona y la caída de los Talibán, se recurre a todas. Si se atiende a la calidad de la información en función de la diversa naturaleza de las fuentes empleadas se podría concluir que los conflictos con mayores puntos de vista son las coberturas que hicieron Gervasio Sánchez y Ángeles Espinosa. En caso de apostar por la cantidad de fuentes empleadas, el conflicto mejor tratado sería de nuevo la guerra contra los Talibán, pues cuenta con 408 fuentes, el mayor número de unidades de análisis.

Teniendo en cuenta el análisis cualitativo a partir de las crónicas y las entrevistas en profundidad examinadas se concluye que el predominio de las fuentes de información no es sinónimo de accesibilidad a las mismas. En el caso de las Oficiales, tanto en las informaciones de Alfonso Rojo durante la guerra del Golfo y la invasión de Irak, donde predominaron las informaciones procedentes de las fuentes militares, como en las de Ángeles Espinosa en la caída de los Talibán, la censura y las contradicciones estuvieron muy presentes en sus crónicas. En el caso de la Segunda Intifada y en la Guerra Civil en Sierra Leona, las informaciones fluyeron con normalidad, al contrario de lo que ocurrió en las tres anteriores, en las que la labor del periodista estuvo a expensas de los intereses de las fuentes oficiales.

En el caso de los testigos, no se podría hablar de una información forzada como en el supuesto anterior pero sí condicionada en dos coberturas concretas. En la Guerra del Golfo, Alfonso Rojo se vio obligado a trabajar sin salir del hotel al Rashid por lo que su labor como testigo directo no fue completa, pues apenas pudo presenciar la guerra. Una situación similar le ocurrió a Ángeles Espinosa si se tiene en cuenta su ubicación en el país vecino, difícil para entrevistar a testigos presenciales a pie de batalla.

La permanencia de Alfonso Rojo en el hotel tampoco le permitió localizar fuentes documentales en 1991. En el caso de la Segunda Intifada, aunque las informaciones de Juan Cierco no fueron condicionadas, no logró contrastarlas. Durante la guerra contra los Talibán y la invasión de Irak, Espinosa y Rojo también sufrieron los efectos de la censura, que condicionaron sus trabajos. 
Los resultados del análisis de la fuente Ayuda en la Guerra Civil en Sierra Leona ahondan en la libertad de Gervasio Sánchez para acercarse a los misioneros y las oenegés al igual que le ocurrió a Ángeles Espinosa. Sin embargo, en este segundo caso, la enviada especial cubrió el conflicto contra los Talibán auspiciada por oenegés por lo que su información podría estar condicionada si se tiene en cuenta la necesaria colaboración con una fuente que facilita la estancia en el país en guerra.

El acceso a los Observadores, Analistas o Expertos también fue decisión de los periodistas, motivo por el cual no se podría hablar de una información condicionada salvo en aquellos casos en los que el experto solicita el anonimato, que resulta perjudicial para la credibilidad de la información.

Como conclusión, se observa cómo las fuentes oficiales, las testimoniales y las documentales, ocupan los primeros puestos en la suma del estudio cuantitativo y cualitativo en cuanto a número de unidades y su capacidad para condicionar a los reporteros que sufrieron su censura o recibieron una información contradictoria. Por el contrario, las fuentes menos utilizadas, Ayuda y Observadores, fueron las más imparciales a la hora de transmitir las informaciones a los reporteros. En definitiva, se abusa de fuentes de información que a priori pautan la forma de proceder de los periodistas. Una solución para esta circunstancia es el uso de distintas fuentes siempre y cuando su selección se haga de forma libre por el corresponsal, solo así podrá enriquecer las informaciones.

\section{Referencias bibliográficas}

ALLEN, Tim y SEATON, Jean (1999): The media of confict. War Reporting and Representations of Ethnic Violence. London and New York, Zed Books.

ASOCIACIÓN DE EDITORES DE DIARIOS ESPAÑOLES (2010): Libro Blanco de la Prensa Diaria 2010. Madrid, AEDE.

BORRAT, Héctor (1989): El periódico, actor político. Barcelona, Gustavo Gili.

CHOMSKY, Noam (2003): Ilusiones de Oriente Medio. Con la ilusión de ¿Paz en Oriente Medio? Reflexiones sobre justicia y nacionalidad. Madrid, Editorial Popular.

HASS, Amira (2005): Crónicas desde Ramala. Una periodista en territorio ocupado. Traducción de José Luis Gil Arista. Barcelona, Galaxia Gutenberg. Círculo de Lectores.

KAPUSCINSKI, Ryszard (2002): Los cínicos no sirven para este oficio. Sobre el buen periodismo. Barcelona, Anagrama.

EL PAÍS (1990). Libro de Estilo. Madrid, Ediciones El País.

MERINO, María Jesús (coord., 2010): Introducción a la investigación de mercados. Madrid, ESIC Editorial.

MORENO, Pastora (1999): "Expresiones y contenidos del mensaje en periodismo escrito". Revista Latina de Comunicación Social, no 43. http://www.ull.es/publicaciones/latina/a1999fjl/69pas.htm. 
PIZARROSO, Alejandro (2005): Nuevas guerras, vieja propaganda (de Vietnam a Irak). Madrid, Cátedra (Grupo Anaya, S.A.).

PODESTÁ, Carolina (2005): "Iraq: una sucesión de diálogos desde el corazón del desorden". Cuadernos de Periodistas, volumen 0, Asociación de la Prensa de Madrid, pp. 51 - 59. http://www.apmadrid.es/content/view/450/190/

RASHID, Ahmed (2001): Los talibán. El Islam, el petróleo y el nuevo 'Gran Juego' en Asia Central. Barcelona, Península.

ROJO, Alfonso (1995): Reportero de guerra, Barcelona, Planeta.

SAID, Edward (1981): Covering Islam. How the media and the experts determine how we see the rest of the world. New York, Pantheon Books.

SAHAGÚN, Felipe (1986): El Mundo fue noticia. Corresponsales españoles en el extranjero: La información internacional en España. Madrid, Fundación Banco Exterior.

SONTAG, Susan et al (2002): El mundo después del 11 de septiembre de 2001. Barcelona, Ediciones Península.

\section{Entrevistas de la autora}

ARMADA, Alfonso (2007): Entrevista en Madrid, 30 de octubre.

AYESTARÁN, Mikel (2008): Entrevista en línea, 9 de noviembre.

CAMACHO, Ana (2008): Entrevista en Madrid, 2 de abril.

CIERCO, Juan (2008): Entrevista en Madrid, 6 de noviembre.

ESPINOSA, Ángeles (2006): Entrevista en Madrid, 14 de junio.

G. PRIETO, Mónica (2008): Entrevista en línea, 11 de octubre.

LEIVA, Mónica (2008): Entrevista en línea, 19 de noviembre.

LOBO, Ramón (2007): Entrevista en Madrid, 29 de diciembre.

PEREGIL, Francisco (2008): Entrevista en Madrid, 13 de febrero.

ROJO, Alfonso (2005): Entrevista en Molina Seca, León, 9 de mayo.

SÁNCHEZ, Gervasio (2007): Entrevista en Madrid, 10 de octubre. 